\title{
Comparison of different power-split hybrid architectures using a global optimisation design method
}

\author{
E. Vinot \\ French Institute of Science and Technology for Transport, \\ Development and Networks (IFSTTAR), \\ 25 Avenue François Mitterrand, \\ Bron Cedex, 69675, France \\ Email: emmanuel.vinot@ifsttar.fr
}

\begin{abstract}
Power-split hybrid electric vehicles (PS-HEV) are the most efficient solution to reduce fuel consumption using electric hybridisation of vehicles. However, different architectures exist or can be developed and it is difficult to perform a fair comparison between these solutions. A global design approach, optimising the size of the components and using optimal energy management can be a good way to compare different PS-HEV architectures. This paper presents a method to size and design HEV in an optimal manner and to compare this vehicle on different objectives: fuel consumption, battery size, and global volume of the system. The method is then applied to four SP-HEV based on existing architectures (Toyota Hybrid System, Opel Ampera) and on alternative solutions (electrical variable transmission and serial-parallel architecture).
\end{abstract}

Keywords: HEV; hybrid electric vehicle; optimal global design; split-power architectures.

Reference to this paper should be made as follows: Vinot, E. (2016) 'Comparison of different power-split hybrid architectures using a global optimisation design method', Int. J. Electric and Hybrid Vehicles, Vol. 8, No. 3, pp.225-241.

Biographical notes: Emmanuel Vinot received his Engineering of Ecole national Supérieur d'Electricité de Grenoble (1997), the MS in Electrical Engineering from the Laval University, Québec, Canada (1998) and the $\mathrm{PhD}$ from the Electrotechnic Laboratory of the National Polytechnique Institute of Grenoble (INPG), France, in 2000. Currently, he is working in the French Institute of Science and Technology for Transport, Development and Network (IFSTTAR) in the hybrid vehicle team. His main interests are systemic models of vehicle and components, system management optimisation, and system and electrical machine design.

\section{Introduction}

Among the hybrid vehicle architectures, the power-split hybrid electric vehicles (PS-HEVs) have been proven to be the most efficient (Chan, 2002; Ehsani et al., 2007; Miller, 2004; Vinot et al., 2007). Splitting the power flow in a combined serial and 
parallel way and decoupling the engine and wheel speeds, such architectures allow a fuel consumption reduction which can reach $40 \%$ in urban driving conditions. Their complexity (at least two electrical machines) is compensated by the economy on fuel consumption and their driving comfort. In fact, they behave like constant variable transmission (CVT) and do not need any gear box. Thus the manufacturers frequently choose this solution of hybridisation.

Several PS_HEVs exist. The Toyota hybrid systems (THSs) are well known (Muta et al., 2004). Opel uses another system based on planetary gear in the Ampera (Sciarretta et al., 2014). Other solutions like electrical variable transmission (EVT) (Miller, 2006; Hoeijmakers and Ferreira, 2006) or two clutches series-parallel HEV are currently studied (Trigui et al., 2012).

It becomes then difficult to perform an objective comparison between these solutions. Especially in the cases of new potential solutions which suffer from the comparison with existing and improved solutions. It has been shown that a fair comparison can only be performed using global optimised design taking into account the components of the systems and the energy management (Zhang et al., 2009; Desai and Williamson, 2009; Buerger et al., 2010; Bertram et al., 2011; Silvas et al., 2014; Reinbold et al., 2013; Reinbold et al., 2016).

Indeed, it is well known that a key point of the efficiency of the hybrid architectures is the power energy management, i.e., the choice of hybrid or electric mode and the energy sharing between the ICE and the EM (Chau and Wong, 2002). But the energy management, the size of the components (ICE, battery, electrical machine) and other system parameters (gear ratio especially) highly interfere in the design process of a hybrid vehicle.

This paper compares four PS-HEVs architectures using a global design process (Vinot et al., 2015) (Figure 1). To avoid the non-monotonic effect induced by heuristic energy management methods, offline power management using determinist dynamic programming (DDP) is included in the global process. The DDP is used to evaluate the fuel consumption to be minimised on different driving representative cycles.

The main process is based on a genetic algorithm; it is then easy to obtain Pareto fronts for the different architectures.

Section 2 presents the method used to obtain optimal design of PS-HEVs. Section 3 describes in detail the four studied architectures. Then, Section 4 presents, for each architecture, 2D Pareto fronts representing fuel consumption vs. battery number of elements. Finally, results obtained with three objectives -number of battery elements, fuel consumption and volume of the system (engine and machine) - are presented.

\section{Design proposed process}

Figure 1 presents the proposed general optimisation process to design in a systemic way a hybrid vehicle (Vinot et al., 2015). The aim of this method is to minimise objectives such as fuel consumption on a driving cycle and cost or size of the components. This is performed using optimal energy management and acting on parameters such as gear ratio, scaling factor on the machine and engine sizes and number of elements of the battery pack. For energy management, an optimal method is embedded in the global 
optimisation process. This is a good way to avoid the non-linear and non-monotonic effect of rule-based energy management (Desai and Williamson, 2009; Buerger et al., 2010).

Figure 1 Global design principle (see online version for colours)

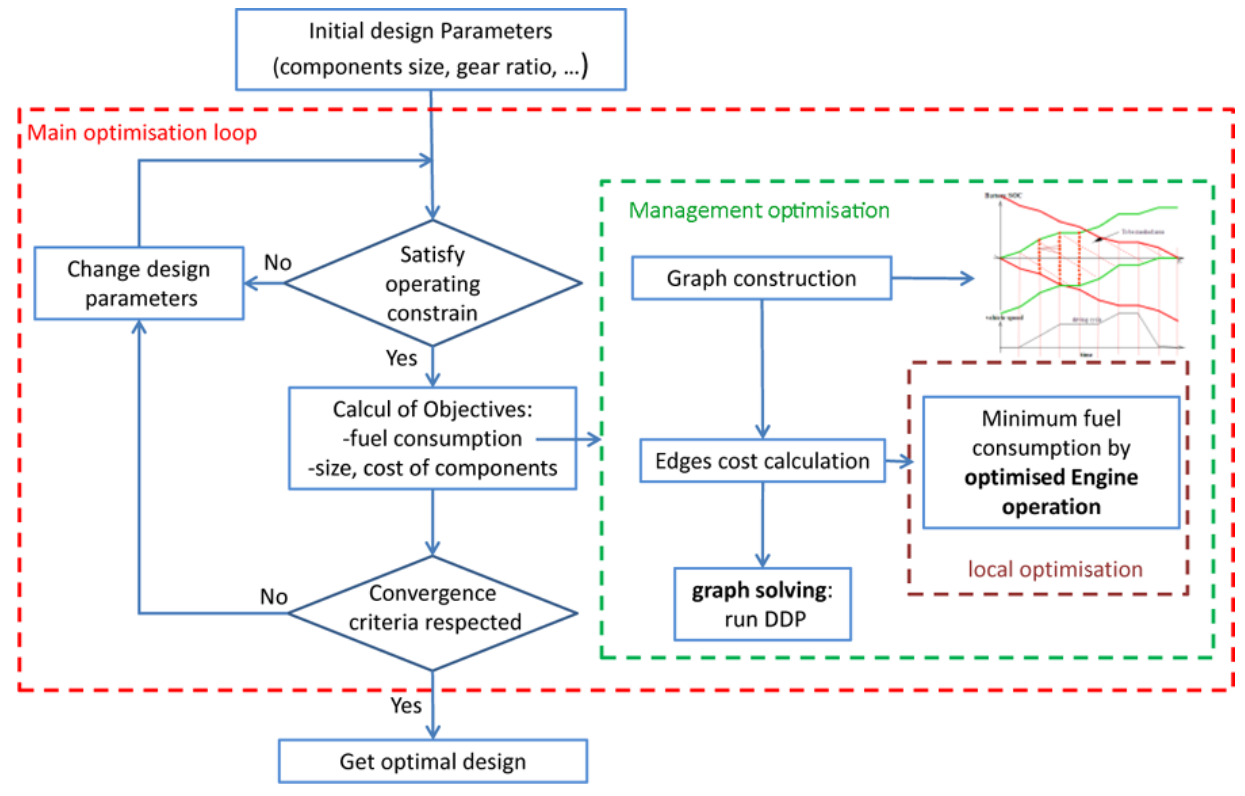

Moreover, in the case of PS-HEV architectures, the decoupling between the wheels and the engine introduces an additional degree of freedom and allows choosing the engine operating point (torque and speed) independently of the vehicle operations. This choice is performed minimising the fuel consumption at each time step, for each possible operation of the system, i.e., a local optimisation is performed on each edge of the DDP graph (Vinot et al., 2012).

The main optimisation algorithm can be based on derivative methods, surrogate models or genetic-based methods. Methods based on gradient require knowing the derivative of the objective function along the design parameters. In our case, as the objective is calculated by DDP, it is only possible to be derived by means of finite differences. This is time consuming and the DDP graph sampling may interfere on the result. A surrogate method was previously tested (Reinbold et al., 2012) and presents good results with a small number of calls to the objective function but it is a mono objective method. A method based on genetic algorithm (GA) has then been chosen. It presents the advantage to easily provide Pareto fronts on multi-objective problems and presents a good convergence for problems considering HEV (Silvas et al., 2014). However, a high number of calls to the objective function are necessary to obtain accurate results (typically 200 generations of 20 individuals leading to 4000 evaluations of the objective function). Thus, the objectives and the constraints have to be calculated in an efficient way. DDP has been improved and allows the evaluation of the fuel consumption objective in a couple of seconds (Vinot, 2014). In the scope of this paper, the Matlab NSGA-II algorithm was used to provide a set of Pareto-optimal solutions. 
In our cases, the $0-100 \mathrm{~km} / \mathrm{h}$ acceleration is constrained to a maximum of $12 \mathrm{~s}$ and the vehicle maximum speed is constrained to a minimum of $160 \mathrm{~km} / \mathrm{h}$. The calculus of these constraints may be also time consuming if calculated in a classical forward way using the system control loops, e.g., the global required torque generated by the corrector on vehicle speed, or the close loop control on the EM torque. Thus, the maximum acceleration capability is calculated neglecting the control loops and the variables are equal to the references or at least a time constant is taken into account.

\section{Architectures}

The following section presents four PS_HEVs architectures which have been compared using the previously presented method. Using this method, since sizing and energy management are optimal, a fair comparison can be performed between the architectures. The studied architectures are:

- The well-known THS.

- The architecture used in Opel Ampera or Chevrolet Volt also based on planetary gear. Note that we consider only vehicles with non-rechargeable capabilities, i.e., operating in charge sustaining mode.

- $\quad$ The electrical variable transmission (EVT) architecture, frequently presented as a possible concurrent to the planetary gear-based system.

- The two clutches serial-parallel HEV, which is not a real PS-HEV but a relatively simple architecture working in parallel or serial mode.

\subsection{THS}

Figure 2 presents the THS (Muta et al., 2004; Vinot et al., 2008). It is mainly composed of an internal combustion engine (ICE), an electrical motor (EM1) directly linked to the transmission, and a second electrical machine (EM2) linked to the ICE via a planetary gear (PG). The PG is connected to the transmission by its ring gear. Moreover, the two electrical machines are connected to a power battery by means of inverters.

Figure 2 Toyota hybrid system architecture (THS) (see online version for colours)

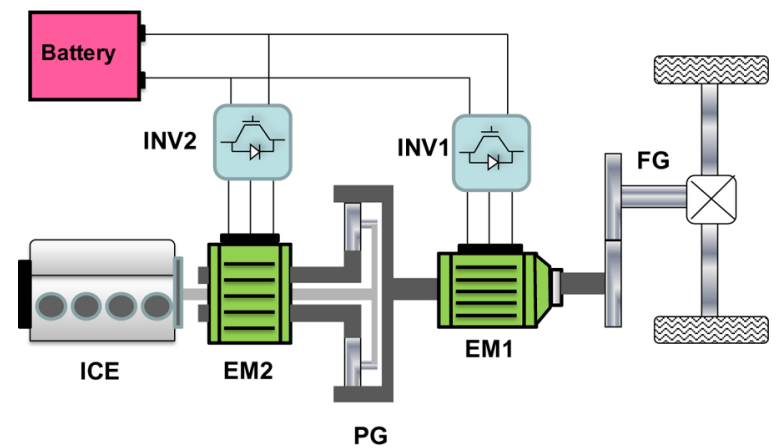




\subsection{Opel Ampera}

Figure 3 presents another planetary gear-based architecture used in Opel Ampera or Chevrolet Volt (Sciarretta et al., 2014). In the following of this paper, for convenience, we called it PS-SH.

Figure 3 Opel Ampera architecture (PS_SH) (see online version for colours)

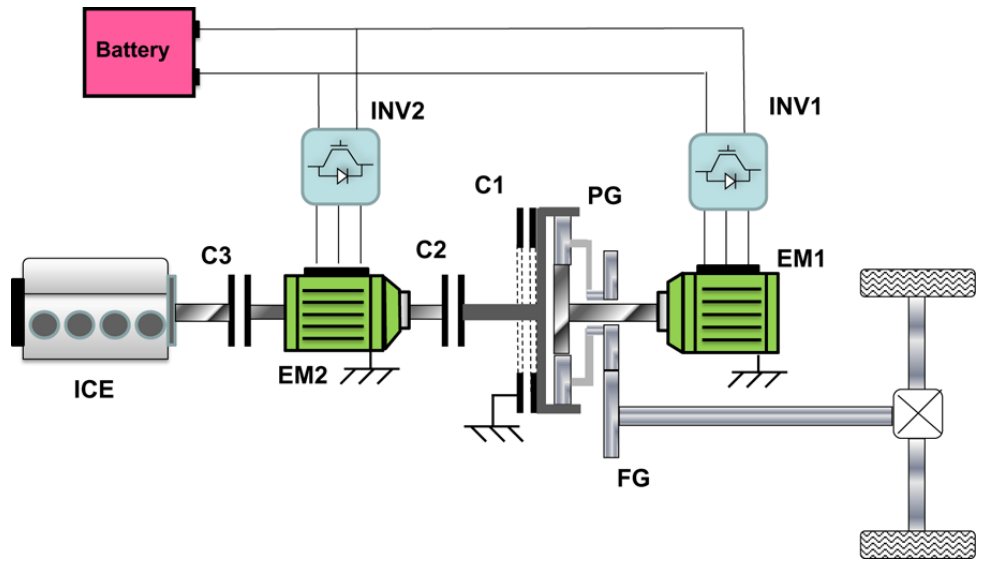

This architecture uses a planetary gear to split the power in parallel and serial flow but the connections are different from those of the THS. A first electrical machine (EM1) is connected to the sun gear. A second machine is connected to the ring gear by means of a clutch (C2). Finally, the engine is also connected to the ring gear by mean of clutch 3 . The planetary gear is linked to the wheel. And another clutch $(\mathrm{C} 1)$ allows fixing the ring gear in electrical mode if using only EM1.

Owing to the three clutches, several modes of power flow circulation exist (Sciarretta et al., 2014):

- An electric mode using only EM1 with C1 locked.

- $\quad$ An electric mode using EM1 and EM2 (C1, C3 open, C2 locked). This mode allows reducing the machine speed and can improve the overall powertrain efficiency. In our simulation, the best system operating point is calculated on every edge of the graph (local optimisation, Section 2).

- $\quad$ A serial HEV mode (C1, C3 locked, C2 open).

- A power split mode (C1 open, $\mathrm{C} 2, \mathrm{C} 3$ locked). In this mode, as in THS, the ICE speed can be chosen depending on the EM2 speed. The best system operating point is also calculated on every edge of the graph.

\section{$3.3 \quad E V T$}

Figure 4 presents the EVT (Miller, 2006; Hoeijmakers and Ferreira, 2006). This architecture is composed by two electrical machines (EM1 and EM2). EM2 possesses a rotating stator connected to the ICE by means of a gear. It allows operating the ICE and 
machine in more efficient areas (Vinot et al., 2012). Note that in a global sizing process the gear ratio can be equal to 1 (equivalent to a direct connection). The rotors of EM1 and EM2 are connected to the shaft linked to the final gear (FG). Integrated EVTs exist which embedded the two machines in one with two rotors (Cheng et al., 2010). In the scope of this paper, the machines are modelled using efficiency maps. The geometry of the EVT with embedded electrical machines or not, is then not taken into account.

Figure 4 EVT architecture (see online version for colours)

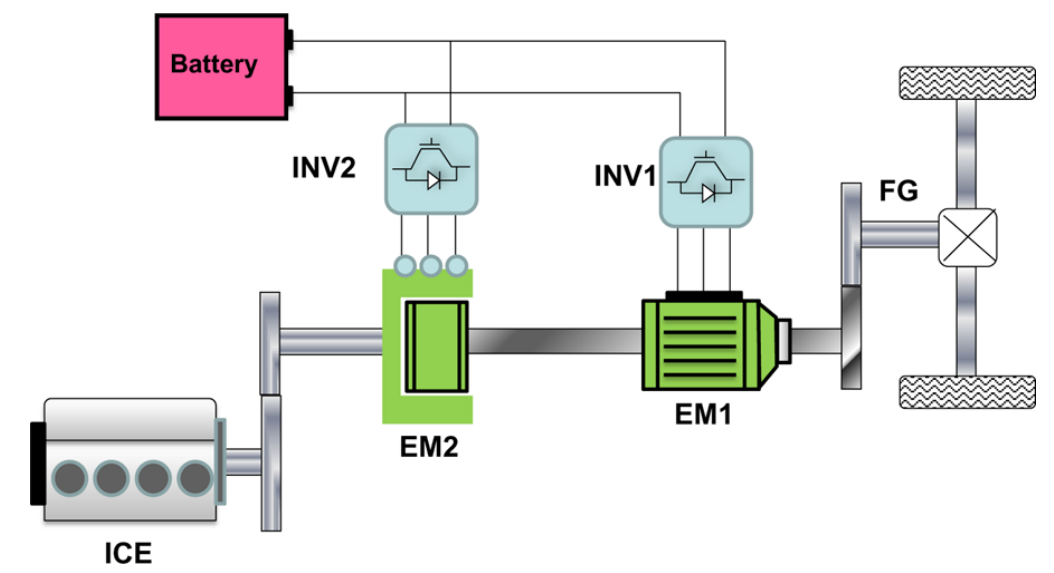

\subsection{Two clutches serial-parallel HEV}

Figure 5 presents the two clutches serial-parallel architecture (TC-SPH) (Trigui et al., 2012). In this architecture, the ICE and the two electrical machines are on the same shaft. Two clutches are inserted between the ICE and EM2 and EM2 and EM1. Thus depending on the state of the clutches, parallel mode ( $\mathrm{C} 1$ and $\mathrm{C} 2$ closed) or serial mode $(\mathrm{C} 1$ open $\mathrm{C} 2$ closed) are possible. This is not a real split power architecture but as it is relatively simple it can be interesting to be compared with the others architectures.

Figure 5 Two clutches series parallel architecture (TC-SPH) (see online version for colours)

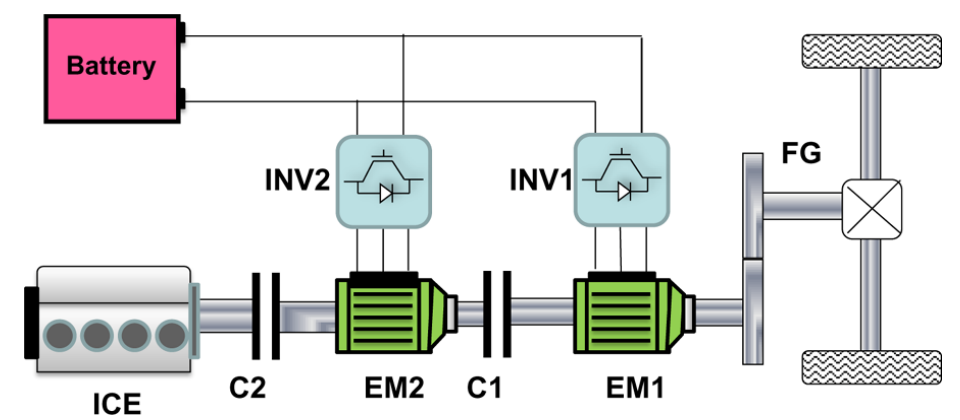

For the four previously presented methods, the optimisation variables are presented in Table 1. 
Table 1 Optimisation variables for the four architectures

\begin{tabular}{lcccc}
\hline & $T H S$ & $P S-S H$ & $E V T$ & $T C-S P H$ \\
\hline ICE power & $\mathrm{x}$ & $\mathrm{x}$ & $\mathrm{x}$ & $\mathrm{x}$ \\
EM1 power & $\mathrm{x}$ & $\mathrm{x}$ & $\mathrm{x}$ & $\mathrm{x}$ \\
EM2 power & $\mathrm{x}$ & $\mathrm{x}$ & $\mathrm{x}$ & $\mathrm{x}$ \\
ICE gear ratio & & & $\mathrm{x}$ & \\
PG ratio & $\mathrm{x}$ & $\mathrm{x}$ & & \\
\hline
\end{tabular}

\section{Vehicles modelling}

This section presents briefly the model used in the global optimisation process for the calculation of the dynamic constraints and the fuel consumption (using DDP). In both cases, backward simulations (upstream from wheel to engine and battery) are performed.

The component models of the different architectures are based on the VEHLIB library (Jeanneret et al., 1999) which provides an energetic and systemic modelling. The engine is modelled with a brake specific fuel consumption (BSFC) maps (Figure 6) associated to a first order filter to take into account the dynamic of the torque response. The electrical machines are modelled using efficiency maps (Figure 7).

Figure 6 Engine brake specific consumption maps (see online version for colours)

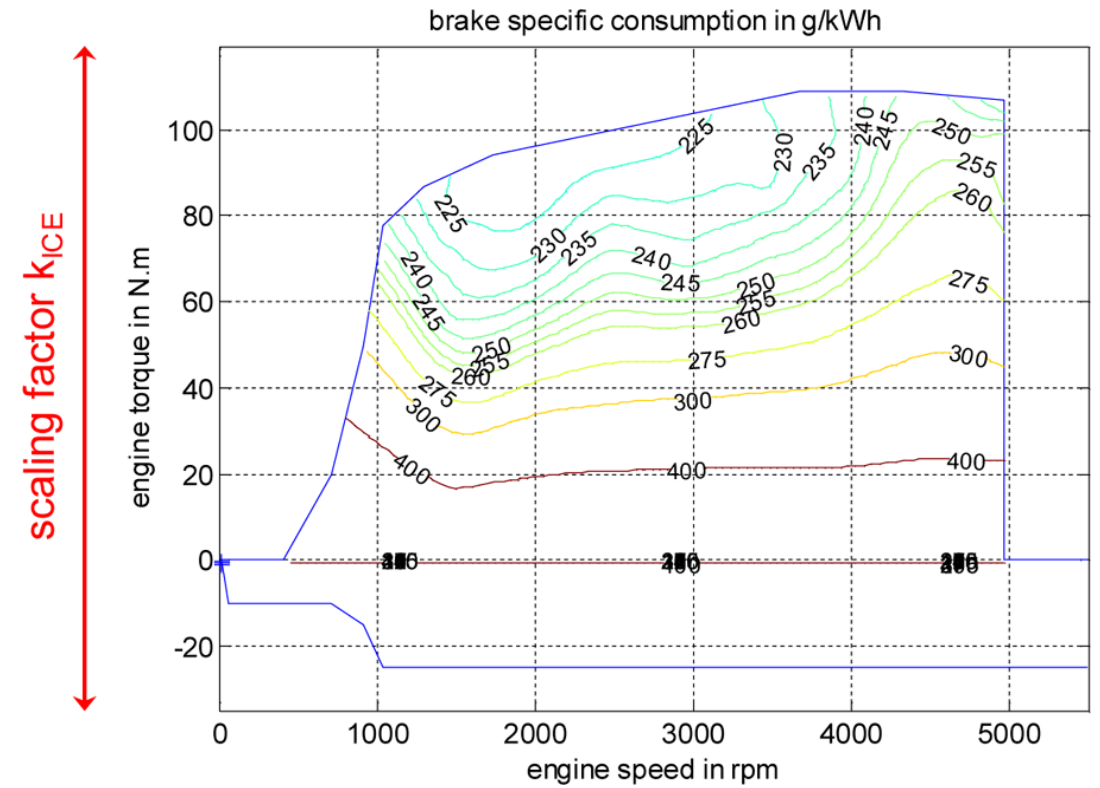

The sizes of the ICE and EMs change according to scaling factors applied on the torque (Figures 6 and 7). For EMs, the maximum torque, the losses and the weight are multiplied by a scaling factor $k_{E M}$. The inertia is multiplied by $\left(k_{E M}\right)^{5 / 3}$. For the ICE, the maximum torque, the fuel consumption and the weight are multiplied by $k_{\mathrm{ICE}}$. The inertia is multiplied by $\left(k_{\mathrm{ICE}}\right)^{5 / 3}$. 
Figure 7 Electrical machine EM1 efficiency map (see online version for colours)

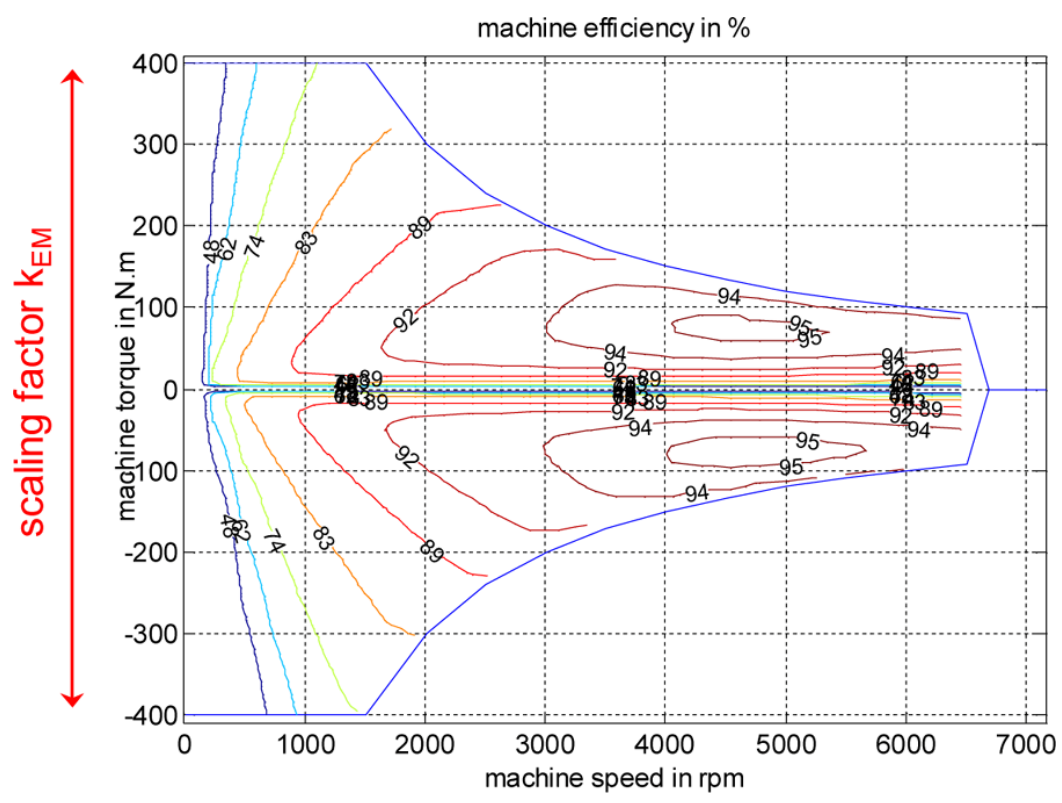

The battery model consists of an equivalent electric circuit with an open circuit voltage $E_{\text {bat }}$, an internal serial resistance $R_{\text {bat }}$, and a Faradic efficiency $\eta_{f} . E_{\text {bat }}$ depends on the SOC and the temperature. $\eta_{f}$ depends on the SOC and the current sign. $R_{\text {bat }}$ depends on the SOC, the temperature and the current sign. Look up tables obtained by experiments are used. The temperature is fixed for all the driving cycle and chosen at the beginning of the cycle. At this stage of development, no thermal model is used, and the parameters remain constant vs. temperature during all the driving cycle.

For the four previously presented methods, the optimisation variables are presented in Table 1. For each architecture, the sizes of the ICE and of the two electrical machines are optimised. The gear ratio of the final gear, of the gear on the ICE shaft (if it exists) and ratio of the planetary gear are also optimised in the global proposed method. These parameters are the variables of a global genetic algorithm (main optimisation loop), used to perform a Pareto front with two or more objectives. Two of these objectives can be the numbers of batteries and the fuel consumption (cf. Section 5).

The fuel consumption is calculated using discrete dynamic programming (DDP) in a known in advance driving cycle (Bellman, 1957; Bertsekas, 1995; Vinot et al., 2007), (management optimisation 1, Figure 1). A good representation of this optimisation problem is a SOC vs. time graph (Figure 8) limited by the maximum battery charge and discharge capabilities. This graph is regularly sampled in time and SOC. The points of two consecutive columns are linked by oriented edges associated to fuel consumption. This fuel consumption depends on the drive cycle profile and the SOC variation between the two points of an edge. The sum of fuel consumption of the edges on a trajectory provides the objective to minimise. The DDP programming method is then applied to find the best trajectory in an efficient way. SP-HEV architectures present an additional degree of freedom, i.e., for fixed driving conditions and fixed battery current you can choose the ICE operating point. In our case, using dynamic programming, the ICE 
operating point is chosen in order to minimise the fuel consumption in each edge of DDP (Vinot et al., 2012).

Figure 8 DDP principle (see online version for colours)

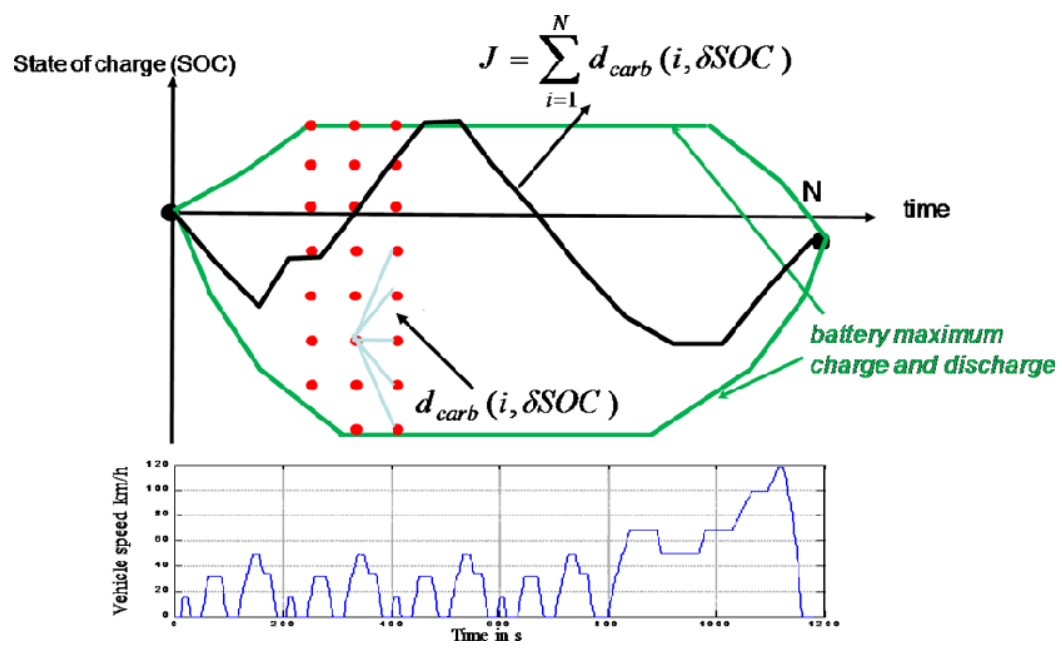

\section{Results in cases of two objectives}

Figures 9-12 present the Pareto front (battery number of elements) vs. fuel consumption obtained for the four previously presented architectures using the global optimisation method presented in Section 2. The results are presented for urban, road, highway and combined driving conditions.

Figure 9 Pareto front battery number of elements vs. fuel consumption in urban driving condition (see online version for colours)

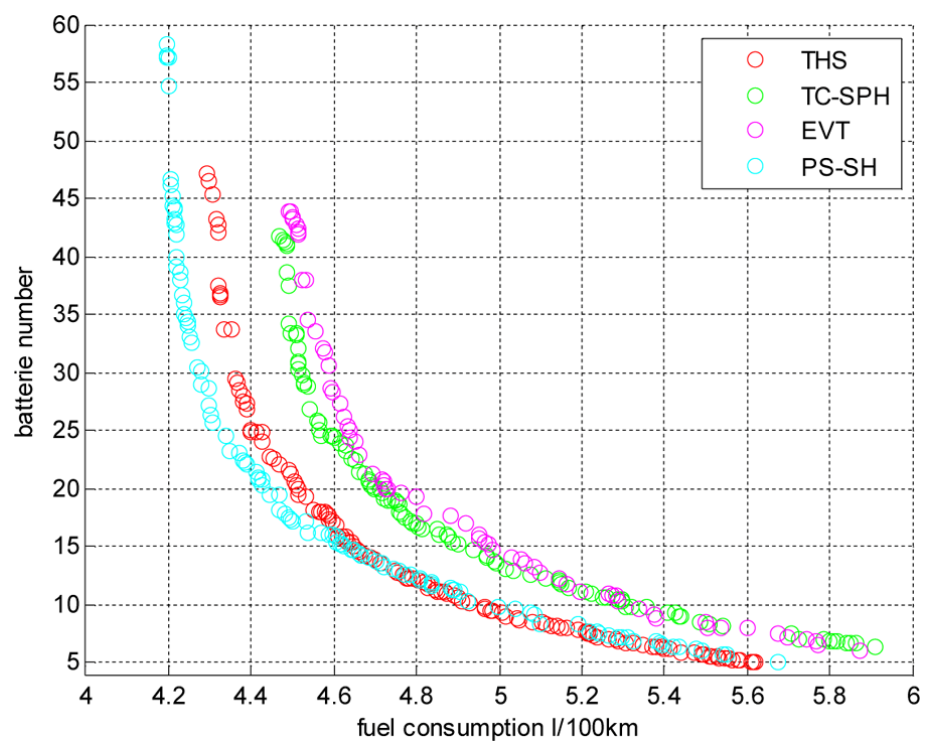


Figure 10 Pareto front battery number of elements vs. fuel consumption in road driving condition (see online version for colours)

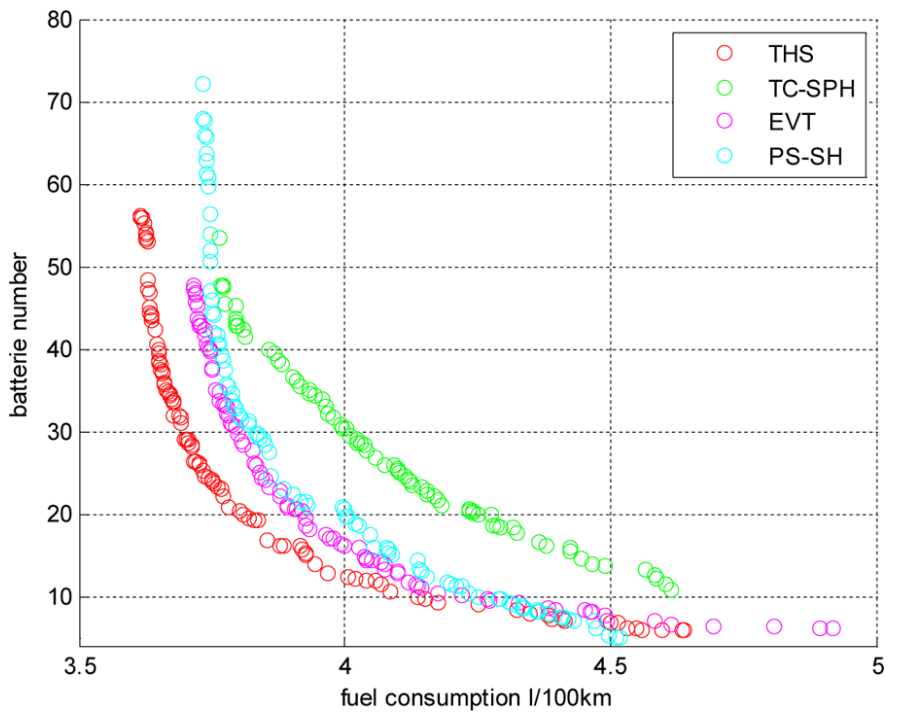

Figure 11 Pareto front battery number of elements vs. fuel consumption in highway driving condition (see online version for colours)

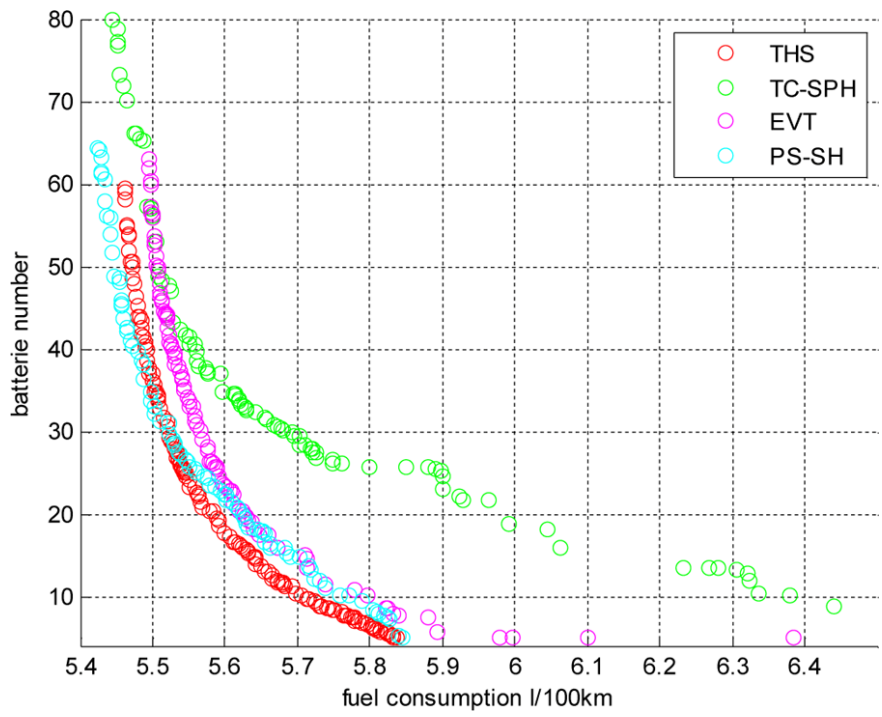

During the design, it appears that some characteristics are highly dependent on the driving cycle and the number of batteries (EM2 and engine mechanical power). It is thus difficult to choose the size of the components and the gear ratio for a vehicle whatever the use is.

A good solution to select the parameters, according to the driving cycle may be to perform the same optimisation with a weighted objective. The objective becomes:

$$
J=\alpha \cdot F C_{\text {urban }}+\beta \cdot F C_{\text {road }}+\gamma \cdot F C_{\text {highway }},
$$


where $F C_{\text {urban }}, F C_{\text {road }}, F C_{\text {highway }}$ are the fuel consumptions, respectively, in urban, road, and highway conditions. $\alpha, \beta$ and $\gamma$ can be fixed using the mean travelled distance in urban, road and highway conditions for a given population. In France, according to Eurostat data, (Eurostat, 2016), these values are, respectively, 0.4, 0.3 and 0.3.

Figure 12 Pareto front battery number of elements vs. fuel consumption in mixed driving condition (see online version for colours)

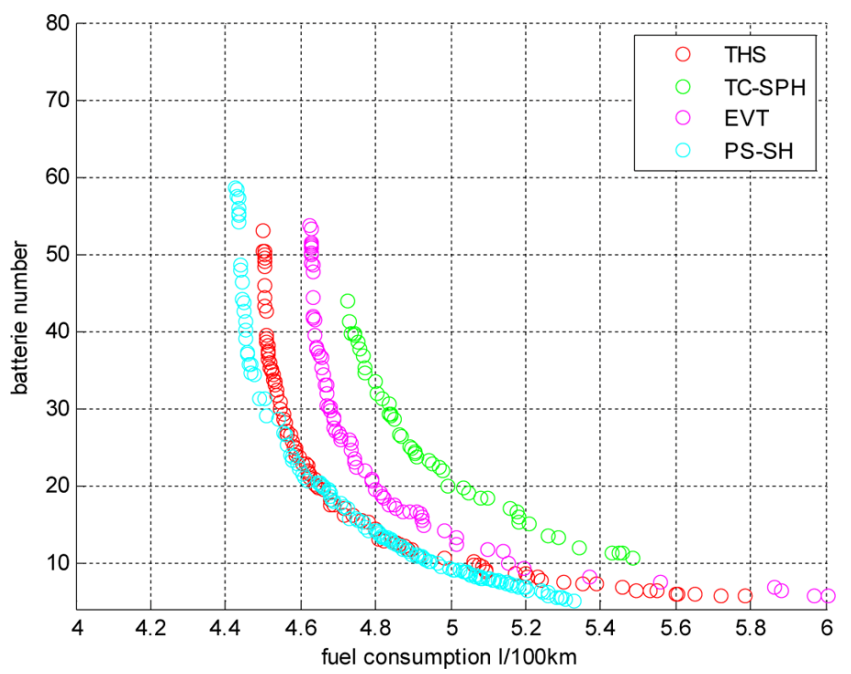

Figures 9-12 shows that regarding fuel consumption, the PS-SH (Figure 3) architecture presents globally the best fuel economy regarding different driving conditions. This is mainly owing to the presence of the three clutches, two of them connected to the planetary gear. They allow to fix the ring and the planetary carrier of the planetary gear and the EM2 machine in certain mode. Useless losses in these components can then be avoided. This is not the case with THS architecture where, for example in electric mode, the sun and the ring of the planetary gear is running (some time at high speed). The rotor of EM2 (which is a permanent magnet machine) is also running creating mechanical and hysteresis losses in the machine.

The THS architecture (Figure 2) presents also good fuel economy compared to EVT and TC-SH whatever the number of elements of the battery pack is. The only drawback is, as mentioned above, the losses in the planetary gear and the EM2 when not used.

The EVT (Figure 4) are less efficient. This is mainly owing to the fact that the operating point of the ICE and EM cannot be chosen with enough degrees of freedom. In particular, EM2 is often constrained to operate in an area with relatively bad efficiency (Vinot et al., 2014), even if a gear is added between ICE and EM2. This is particularly penalising in urban driving conditions at low operating speed. In such conditions, with architectures based on planetary gear, the ICE and EM can usually operate at relatively higher speed in best efficiency area.

The TC-SPH (Figure 5) appears to be the least efficient architecture. In fact, this architecture does not allow power-split mode but only parallel or hybrid mode. Thus, the operating point of the components cannot be chosen with as much possibilities as in real PS-HEV. Moreover, owing to limitations on the engine and EM speed, the serial mode is often used, even with optimal design fixing the final gear ratio. In highway driving 
condition for example, with 30 elements in the battery pack, the serial mode is used around $50 \%$ of the time, whereas it is only used around $1 \%$ of the time with PS-SH.

Table 2 presents some points of the Pareto fronts with the associated found optimal parameters. These results are presented for three sizes of the battery packs (10, 20 and 30 elements). It is noted that for the four architectures, the size of the ICE decreases when the number of elements of the battery pack increases. On the other hand, the size of the electrical machines tends to decrease. It can be explained taking into account that with a smaller ICE, less power has to be split in hybrid mode (this can be especially sensitive on EM2).

Table 2 Sizing results for 10, 20 and 30 battery number of elements in mixed driving condition

\begin{tabular}{|c|c|c|c|c|}
\hline \multirow[b]{2}{*}{ Battery number of elements } & \multicolumn{4}{|c|}{10} \\
\hline & $T H S$ & $P S-S H$ & $E V T$ & $T C-S P H$ \\
\hline ICE power $(\mathrm{kW})$ & 80 & 75 & 71 & 75 \\
\hline EM1 electrical power $(\mathrm{kW})$ & 63 & 70 & 62 & 82 \\
\hline EM2 electrical power $(\mathrm{kW})$ & 47 & 56 & 49 & 72 \\
\hline ICE gear ratio & & & 0.6 & \\
\hline PG ratio & 1.5 & 2.5 & & \\
\hline FG ratio & & & & 3.84 \\
\hline \multirow[t]{2}{*}{ Fuel consumption $(1 / 100 \mathrm{~km})$} & 5.06 & 4.95 & 5.15 & 5.48 \\
\hline & \multicolumn{4}{|c|}{20} \\
\hline Battery number of elements & $T H S$ & $P S-S H$ & $E V T$ & $T C-S P H$ \\
\hline ICE power $(\mathrm{kW})$ & 57 & 65 & 61 & 61 \\
\hline EM1 electrical power $(\mathrm{kW})$ & 51 & 71 & 54 & 70 \\
\hline EM2 electrical power $(\mathrm{kW})$ & 40 & 59 & 46 & 72 \\
\hline ICE gear ratio & & & 0.6 & \\
\hline PG ratio & 1.5 & 2.2 & & \\
\hline FG ratio & & & & 4.09 \\
\hline \multirow[t]{2}{*}{ Fuel consumption $(1 / 100 \mathrm{~km})$} & 4.63 & 4.65 & 4.8 & 4.99 \\
\hline & \multicolumn{4}{|c|}{30} \\
\hline Battery number of elements & $T H S$ & $P S-S H$ & $E V T$ & $T C-S P H$ \\
\hline ICE power $(\mathrm{kW})$ & 48 & 55 & 54 & 52 \\
\hline EM1 electrical power $(\mathrm{kW})$ & 57 & 72 & 58 & 73 \\
\hline EM2 electrical power $(\mathrm{kW})$ & 28 & 42 & 36 & 56 \\
\hline ICE gear ratio & & & 0.5 & \\
\hline PG ratio & 1.8 & 2.2 & & \\
\hline FG ratio & & & & 4.15 \\
\hline Fuel consumption (1/100 km) & 4.54 & 4.5 & 4.68 & 4.83 \\
\hline
\end{tabular}

Comparing the architectures, the powers of the ICE and the electrical machines are similar for equivalent size of battery pack. Except the TC-SPH which presents 
components with a higher power. But it is noted that no constraints are applied on the volume or cost of the systems in this part. For that, the proposed optimal sizing method has been applied taking into account a third objective which is the volume of the global system (part 6).

\section{Results}

This part presents the results obtained applying the optimal proposed method to the four architectures considering three objectives:

- The fuel consumption.

- The number of elements in the battery pack.

- The volume of the system (composed of the ICE and electrical machines). The sum of the volume of each element is chosen as it is representative of the compactness of the system.

It is clear that other objectives or constraints can be chosen or added. Simulation has been performed with five objectives (the volume of each component is one objective). It is not shown here since the Pareto front of five dimensions is difficult to represent.

In a first approximation, the power/volume ratio is supposed to be constant for each element. It is fixed to the value observed on the THS (Table 3 ).

Figure 13 presents the points obtained on the Pareto front for the four studied architectures. The evolution of the fuel consumption vs. the number of elements of the battery pack is presented on the left and the volume on the right.

Table 3 Volume of the components of existing THS

\begin{tabular}{lcc}
\hline & Mechanical power $(\mathrm{kW})$ & Volume $(1)$ \\
\hline Engine (ICE) & 50 & 9.4 \\
Electrical machine EM1 & 30 & 4.7 \\
Electrical machine EM2 & 55 & 39.7 \\
\hline
\end{tabular}

Figure 13 Pareto front number of battery elements vs. fuel consumption in mixed driving condition (see online version for colours)
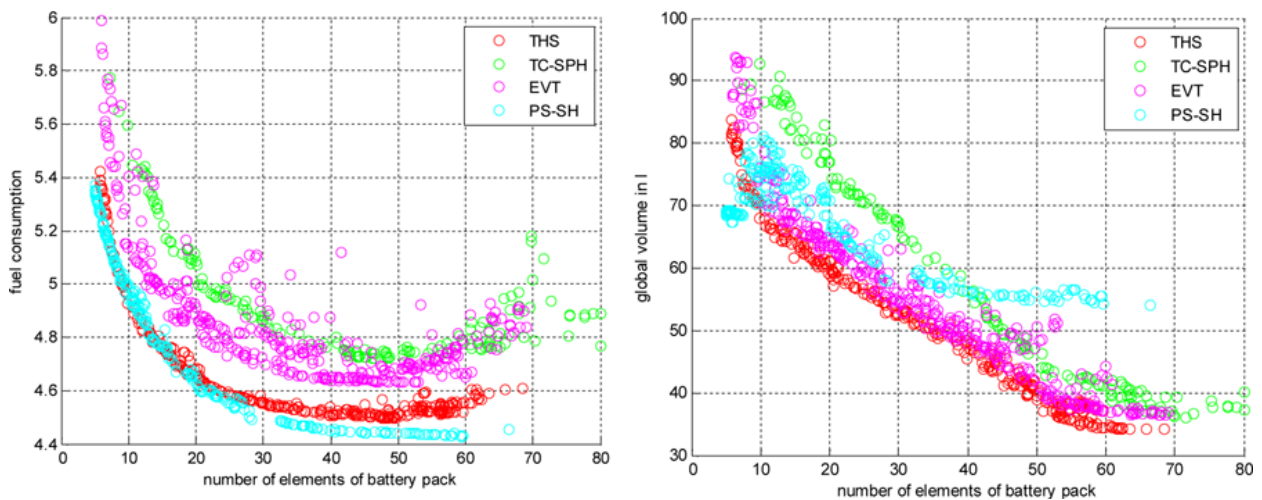
Table 4 presents some points of this Pareto front. The proposed points have been chosen for three sizes of the battery packs $(10,20$ and 30 elements) among those minimising the global volume of the systems. It is noted that the TC-SPH system is the one presenting the highest fuel consumption and the highest volume. This is mainly owing to the serial hybrid mode which imposes big electrical machines. On the other hand, THS and EVT seem to be the most compact architectures. The PS_SH is the most efficient in terms of fuel consumption but seems a little less compact.

Table 4 Sizing results for 10, 20 and 30 battery number of elements in mixed driving conditions

\begin{tabular}{|c|c|c|c|c|}
\hline \multirow[b]{2}{*}{ Battery number of elements } & \multicolumn{4}{|c|}{10} \\
\hline & $T H S$ & $P S-S H$ & $E V T$ & $T C-S P H$ \\
\hline ICE power $(\mathrm{kW})$ & 65 & 75 & 66 & 83 \\
\hline EM1 electrical power $(\mathrm{kW})$ & 52 & 45 & 58 & 82 \\
\hline EM2 electrical power $(\mathrm{kW})$ & 45 & 35 & 48 & 75 \\
\hline ICE gear ratio & & & 0.95 & \\
\hline PG ratio & 1.5 & 1.5 & & \\
\hline Volume (1) & 63 & 66 & 65 & 85 \\
\hline \multirow[t]{2}{*}{ Fuel consumption $(1 / 100 \mathrm{~km})$} & 4.92 & 4.98 & 5.4 & 5.6 \\
\hline & \multicolumn{4}{|c|}{20} \\
\hline Battery number of elements & $T H S$ & $P S-S H$ & $E V T$ & $T C-S P H$ \\
\hline ICE power $(\mathrm{kW})$ & 60 & 59 & 56 & 67 \\
\hline EM1 electrical power $(\mathrm{kW})$ & 46 & 69 & 61 & 77 \\
\hline EM2 electrical power $(\mathrm{kW})$ & 38 & 41 & 50 & 74 \\
\hline ICE gear ratio & & & 0.81 & \\
\hline PG ratio & 1.5 & 1.7 & & \\
\hline Volume (1) & 56 & 60 & 58 & 64 \\
\hline \multirow[t]{2}{*}{ Fuel consumption $(1 / 100 \mathrm{~km})$} & 4.65 & 4.62 & 4.91 & 5.07 \\
\hline & \multicolumn{4}{|c|}{30} \\
\hline Battery number of elements & THS & $P S-S H$ & $E V T$ & $T C-S P H$ \\
\hline ICE power $(\mathrm{kW})$ & 50 & 50 & 51 & 56 \\
\hline EM1 electrical power $(\mathrm{kW})$ & 49 & 70 & 49 & 67 \\
\hline EM2 electrical power $(\mathrm{kW})$ & 31 & 35 & 34 & 54 \\
\hline ICE gear ratio & & & 0.77 & \\
\hline PG ratio & 1.7 & 1.9 & & \\
\hline Volume (1) & 48 & 54 & 50 & 60 \\
\hline Fuel consumption (1/100 km) & 4.55 & 4.48 & 4.81 & 4.86 \\
\hline
\end{tabular}




\section{Conclusion}

A global optimal design method of the size of the components and of the system parameters has been developed and applied on different power-split hybrid architectures. It uses a main genetic algorithm for the system parameters optimisation including an optimal energy management based on DDP. The Pareto front is then performed and allows a post optimisation choice of the size of the vehicle components.

Using this method, a fair comparison of optimal design of four PS-HEV architectures has been performed. The compared architectures are the well-known THS, the Opel Ampera system and two alternative architectures, the EVT and a two clutches serial/ parallel architecture (TC_SPH).

Regarding the fuel consumption, it seems that the Opel system is the most efficient. This can be explained by the presence of three clutches allowing different possibilities of power flow. The THS presents close performances, whereas EVT and TC-SPH, which do not use planetary gear, present higher fuel consumption.

In terms of compactness, a first study with three objectives only based on the volume of each component, shows that the THS and EVT seem the most compact architectures. The TC-SPH, as it operates some time in serial mode, presents a higher volume of components; the electrical machine has to be of equivalent power as those of the ICE.

To make a fair comparison, this work is currently improved in our labs in order to take into account the volume of the systems in a better way. The gear has to be included and the organisation of the components is also an important issue. The cost of the components is also an important issue which may be taken into account as well.

\section{References}

Bellman, R.E. (1957) Dynamic Programming, Princeton University Press.

Bertram, C., Buecherl, D., Thanheiser, A. and Herzog, H. (2011) 'Multi-objective optimization of a parallel hybrid electric drive train', Vehicle Power and Propulsion Conference (VPPC), 2011 IEEE, Chicago, Illinois, USA, pp.1-5.

Bertsekas, D.P. (1995) Dynamic Programming and Optimal Control, Athena Scientific, Belmont, MA.

Buerger, S., Lohmann, B., Merz, M., Vogel-Heuser, B. and Hallmannsegger, M. (2010) 'Multi-objective optimization of hybrid electric vehicles considering fuel consumption and dynamic performance', Vehicle Power and Propulsion Conference (VPPC), 2010 IEEE, Lille, France, pp.1-6.

Chan, C.C. (2002) 'The state of the art of electric and hybrid vehicles', Proceedings of the IEEE, Vol. 90, No. 2, pp.247-275.

Chau, K.T. and Wong, Y.S. (2002) 'Overview of power management in hybrid electric vehicles', Energy Conversion and Management, Vol. 43, No. 15, pp.1953-1968.

Cheng, Y., Espanet, C., Trigui, R., Bouscayrol, A. and Cui, S. (2010) 'Design of a permanent magnet electric variable transmission for HEV applications', Vehicle Power and Propulsion Conference (VPPC), 2010 IEEE, Lille, France, pp.1-5.

Desai, C. and Williamson, S.S. (2009) 'Optimal design of a parallel hybrid electric vehicle using multi-objective genetic algorithms', Vehicle Power and Propulsion Conference, 2009. VPPC'09. IEEE, Dearborn, Michigan, USA, pp.871-876. 
Ehsani, M., Gao, Y. and Miller, J.M. (2007) 'Hybrid electric vehicles: architecture and motor drives', Proceedings of the IEEE, Vol. 95, No. 4, pp.719-728.

Eurostat (2016) Eurostat Statistic on Population Displacement, http://epp.eurostat.ec.europa.eu/ portal/page/portal/transport/data/database

Hoeijmakers, M.J. and Ferreira, J.A. (2006) 'The electric variable transmission', IEEE Transactions on Industry Applications, Vol. 42, No. 4, pp.1092-1100.

Jeanneret, B., Trigui, R., Badin, F. and Harel, F. (1999) 'New hybrid concept simulation tools, evaluation on the toyota prius car', 16th International Electric Vehicle Symposium, Beijing, China, 1999, October, China, pp.1-11.

Miller, J.M. (2004) 'Propulsion systems for hybrid vehicles', IET, Vol. 45, 455 pages.

Miller, J.M. (2006) 'Hybrid electric vehicle propulsion system architectures of the e-CVT type', IEEE Transactions on Power Electronics, Vol. 21, No. 3, pp.756-767.

Muta, K., Yamazaki, M. and Tokieda, J. (2004) Development of New-Generation Hybrid System THS II-Drastic Improvement of Power Performance and Fuel Economy, SAE Technical Paper, Tech. Rep. 2004.

Reinbold, V., Vinot, E. and Gerbaud, L. (2012) 'Global optimization of a parallel hybrid vehicle using optimal energy management', Optimization and Inverse Problems in Electromagnetism (OIPE), 2012, Delft, Netherlands, pp.1, 2.

Reinbold, V., Vinot, E. and Gerbaud, L. (2013) 'Global optimization of a parallel hybrid vehicle using optimal energy management', International Journal of Applied Electromagnetics and Mechanics, Vol. 43, No. 1, pp.115-126.

Reinbold, V., Vinot, E., Garbuio, L. and Gerbaud, L. (2016) 'Optimal sizing of an electrical machine using a magnetic circuit model: application to a hybrid electrical vehicle', IET Electrical Systems in Transportation, Vol. 6, No. 1, pp.27-33.

Sciarrettaa, A., Serraoc, L., Dewangana, P.C., Tonaa, P., Bergshoeffh, E.N.D., Bordonsi, C., Charmpae, L., Elbertd, Ph., Erikssonf, L., Hofmanh, T., Hubacherh, M., Iseneggerh, P., Lacandiag, F., Laveaue, A., Lie, H., Marcosi, D., Nüeschd, T., Onorig, S., Pisub, P., Riosb, J., Silvash, E., Sivertssonf, M., Tribiolig, L., van der Hoevenh, J. and Wue, M. (2014) 'A control benchmark on the energy management of a plug-in hybrid electric vehicle', Control Engineering Practice, Vol. 29, pp.287-298.

Silvas, E., Bergshoeff, E., Hofman, T. and Steinbuch, M. (2014) 'Comparison of bi-level optimization frameworks for sizing and control of a hybrid electric vehicle', Vehicle Power and Propulsion Conference (VPPC), 2014 IEEE, October, Coimbra, Portugal, pp.1-6.

Trigui, R., Vinot, E. and Jeanneret, B. (2012) 'Backward modeling and energy management optimization of a two clutches series-parallel HEV for efficiency assessment', Power Plant and Power System Control Symposium IFAC PPPSC), 2012, Toulouse, France, pp.1-6.

Vinot, E. (2014) 'Time reduction of the dynamic programming computation in the case of hybrid vehicle', Optimization and Inverse Problems in Electromagnetism (OIPE), 2014, Delft, Netherlands, pp.1, 2.

Vinot, E., Reinbold, V. and Trigui, R. (2015) 'Global optimized design of an electric variable transmission for HEVs', IEEE Transactions on Vehicular Technology, Vol. PP, No. 99, pp.1-5.

Vinot, E., Scordia, J., Trigui, R., Jeanneret, B. and Badin, F. (2008) 'Model simulation, validation and case study of the 2004 THS of Toyota Prius', International Journal of Vehicle Systems Modelling and Testing, Vol. 3, No. 3, pp.139-167.

Vinot, E., Trigui, R., Cheng, Y., Bouscayrol, A. and Espanet, C. (2012) 'Optimal management and comparison of SP-HEV vehicles using the dynamic programming method', Vehicle Power and Propulsion Conference (VPPC), 2012 IEEE, October, Seoul, Korea, pp.944-949.

Vinot, E., Trigui, R., Cheng, Y., Espanet, C., Bouscayrol, A. and Reinbold, V. (2014) 'Improvement of an EVT-based HEV using dynamic programming', IEEE Transactions on Vehicular Technology, Vol. 63, No. 1, pp.40-50. 
Vinot, E., Trigui, R., Jeanneret, B., Scordia, J. and Badin, F. (2007) 'HEVs comparison and components sizing using dynamic programming', Vehicle Power and Propulsion Conference, 2007. VPPC 2007. IEEE, September, Arlington, Texas, USA, pp.314-321.

Zhang, B., Chen, Z., Mi, C. and Murphey, Y.L. (2009) 'Multi-objective parameter optimization of a series hybrid electric vehicle using evolutionary algorithms', Vehicle Power and Propulsion Conference, 2009. VPPC'09, IEEE, Dearborn, Michigan, USA, pp.921-925. 